\title{
Key Points of Policing Work at Underground Station of High Speed Railway in Hainan International Tourism Island
}

\author{
Huang, Zhenzhen \\ Police Sports Department, Railway Police College, 450053 Zhengzhou, Henan, China \\ *Corresponding Author.
}

\begin{abstract}
:
The forest coverage rate of Hainan Island is more than $60 \%$, and the forest is an important ecological support for Hainan to build an international tourism island. Aircraft and high-speed railway are the main means of carrying tourists. The high-speed railway station of Meilan Airport is located underground, so the security work is very difficult. This paper analyzes the main risks of Meilan underground station, and puts forward the Policing Work mode suitable for Meilan underground station, which combines the Policing Work with the public security work The construction of international tourism island is combined organically, and the main points of Policing Work are summarized and perfected, which provides a reference for the public security organs to perform the security of export-oriented underground stations.
\end{abstract}

Keywords: International Tourism Island; Ecotourism; Underground Station; Policing Work.

\section{INTRODUCTION}

Hainan has $20 \mathrm{~K}$ hectares of forest land, with a forest coverage rate of over $60 \%$. Tropical natural forests and wild animals and plants are quite rich, which is an important ecological support for Hainan. Tropical rainforest can protect wind, sand and water, which is an important guarantee for the improvement of environmental quality, the foundation for maintaining ecological safety, the potential for green development, the important embodiment of people's livelihood and the sustainable development The basic guarantee of development, the lifeline of the island and the symbol of beauty are of special significance to the construction of Hainan International Tourism Island. With the improvement of forest landscape and the rise of forest food, forest sports, forest experience, forest medical and other forest health industries, Hainan International Tourism Island will add new charm.

As an international tourism island, passengers mainly choose airplanes as the main means of transportation when they enter and leave Hainan Island [1], and passengers mainly choose high-speed railway as the main means of transportation in the island. Meilan Airport, located in Haikou City, Hainan Province, is a comprehensive hub of aviation and railway. Due to its underground location, the security work is difficult, which puts forward new requirements for the railway public security organs Under the situation of full attention and anti-terrorism and stability maintenance, it is necessary to improve the safety awareness of railway public security organs and improve the key points of station Policing Work. 


\section{RISK ANALYSIS OF MEILAN UNDERGROUND STATION}

\subsection{Characteristics of Underground Stations}

Meilan Airport Station of high-speed railway is the only underground station of Hainan Island high-speed railway [2]. There are two platforms and four lines, which are divided into two underground floors. The first underground floor is the station hall floor, which is connected with the transfer channel. The total length of the transfer channel is about $65 \mathrm{~m}$, and passengers can complete the transfer within 2 minutes' walk. The second underground floor is the platform floor, mainly the locomotive driving area and the boarding and alighting passenger area. The station hall floor to the platform floor are connected by four step elevators and four elevators. The total length of the transfer channel connected with the station hall floor is $320 \mathrm{~m}$. The other end of the channel is Meilan Airport terminal, which connects with the airport. The comprehensive transportation center of Haikou Meilan Airport is shown in Figure 1. There is a platform screen door system on the platform floor of Meilan Airport Station, which is not found in the ordinary high-speed railway station. The space in the station is relatively closed, and the space structure is similar to that of the subway station [3]. It is an important proposition for railway public security organs to explore the Policing Working mechanism suitable for Meilan Airport [4].

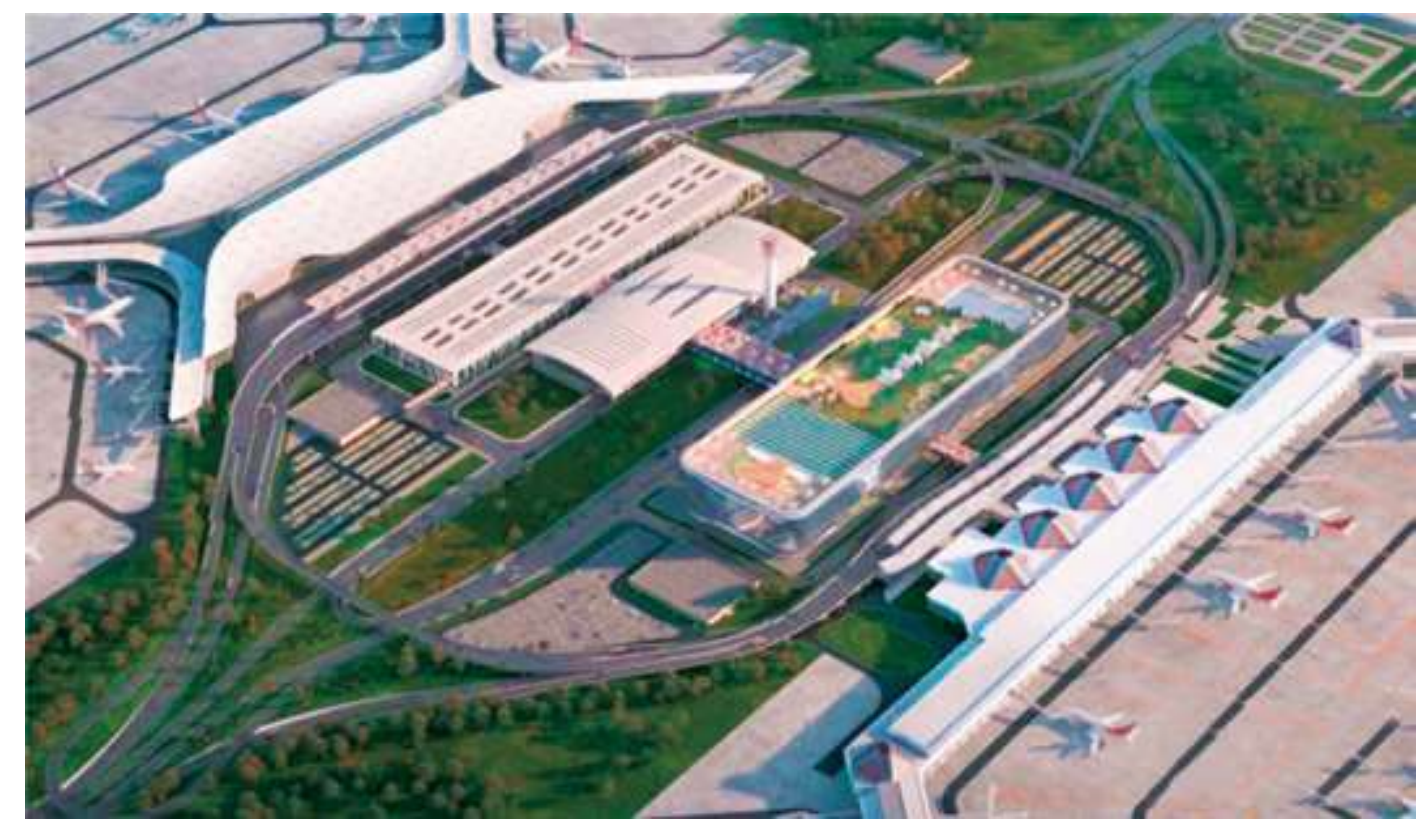

Figure 1. Comprehensive transportation center of Haikou Meilan Airport

\subsection{Passenger Flow Characteristics}

Aircraft is the main means of transportation for passengers in and out of Hainan Island, and high-speed rail is the main means of transportation for passengers in Hainan Island. With the continuous deepening of the construction of international tourism island, the passenger flow is increasing. Relevant foreign studies believe that the critical point of crowd density is 7 people per square meter, otherwise it may lead to crowded stampede accidents [5]. The generation and attraction of passenger flow are shown in formula (1) and (2) respectively.

$$
G_{i}=\left[G_{i 1} \cdots, \quad G_{i j} \cdots, \quad G_{i m} \cdots\right]^{\mathrm{T}}
$$




$$
A_{i}=\left[A_{i 1} \cdots, \quad A_{i j} \cdots, \quad A_{i m} \cdots\right]^{\mathrm{T}}
$$

The passenger flow of key areas can be expressed by formula (3).

$$
T_{i}=\left(G_{i} \times A_{i}{ }^{T}\right)^{\beta_{i}} \times\left[\begin{array}{ccc}
K_{i}{ }^{11} & \cdots & K_{i}{ }^{1 m} \\
\vdots & & \vdots \\
K_{i}^{m 1} & \cdots & K_{i}^{m n}
\end{array}\right]
$$

According to the possible problems caused by large passenger flow, targeted measures must be taken to eliminate hidden dangers and ensure safety. Passenger flow order is the key to safety management. It is necessary to give consideration to the requirements of safety and convenience, improve methods and strengthen cooperation among all parties [6].

\section{MAIN POINTS OF POLICE PRACTICAL WORK IN MEILAN UNDERGROUND STATION}

Railway public security organs should take the opportunity of practical training, innovate the Policing Work mode, and do a good job in public security prevention and control, joint service linkage, security inspection guidance supervision, anti-terrorism prevention, publicity and education.

\subsection{Public Security Prevention and Control}

Meilan underground station has small space, relatively closed, dense passenger flow, fast personnel mobility and complex personnel composition. In order to better maintain the public security and order in the station, the police should strengthen the normal patrol, improve the rate of seeing the police in the station, enhance the sense of safety of passengers, and timely detect crimes in the process of patrol.

In order to ensure the stability of public order and the safe operation of high-speed railway in the station, in view of the situation that people's identity cards are not consistent when they purchase tickets by using other people's identity cards, the Policing Work mode of "prevention first, active recording, information collection and legal attack" is constructed. By collecting and checking personnel information, the police can find or confirm whether their personnel have illegal or criminal behaviors, and control them in time. If the police encounter passengers who do not cooperate when checking the information of the personnel, they should guide them patiently, strengthen the interrogation of the suspicious personnel, and carry out the secondary security inspection of their luggage.

\subsection{Joint Logistics Linkage}

In the process of daily station patrol, it is inevitable that the cooperation of individual departments is not close enough, and the joint service of relevant units in the station is not tacit, which leads to the failure of timely and effective treatment of public security problems. It is urgent to establish the underground station work mode of "highly shared information, highly integrated work content, and deep application of service work". Railway public security organs should combine with the reality of Meilan underground station, establish joint service office with local government, airlines, railway companies and other relevant departments, establish a unified and efficient command platform, and strengthen cooperation with relevant 
departments, Clearly divide the main responsibilities, give full play to the overall combat function in the station, improve the video patrol work mechanism, collect and judge all kinds of information in advance, and formulate a sound and scientific emergency plan, so as to achieve the work effect of rapid response and joint disposal.

\subsection{Anti Terrorism Prevention}

To counter terrorism and maintain stability, we should focus on prevention and early warning. It is necessary to strengthen the basic work of railway anti-terrorism prevention, and realize the pattern of coordinated patrol prevention and control by public security, armed police, emergency, railway companies and other security forces in the station. On the basis of implementing the mode of "taking actual combat as the main task and combining exercises of various departments", the railway public security organs should actively urge railway enterprises to implement the leadership responsibility system of security management and the staff post responsibility system.

Practice the training mode of "shift training, war training in one", and strengthen the anti-terrorism prevention work. The first is to carry out the single police training, and formulate the annual police training plan scientifically and reasonably in combination with the characteristics of Hainan Island High Speed Railway Underground station and the actual situation of Policing Work. The basic purpose of the training is to strengthen the police skills of the railway police, and make the law enforcement activities that can quickly respond to the emergency in the underground station and achieve the legal compliance. In the training institutions, we should not only pay attention to the study of theoretical knowledge, but also pay attention to the actual combat drill, and constantly improve the police's self-protection awareness in the process of actual combat drill. The second is to actively carry out single police combat drills and team combat drills. On the basis of the anti-terrorism mode of "station training" and "team exercise", coordinate with relevant departments and railway enterprises, formulate plans for various emergencies and situations that may occur, strengthen the actual combat synthetic exercise, further determine the norms of synthetic Policing Work, continuously strengthen the emergency response plan of Hainan ring Island high speed railway underground station, and improve its rationality, scientificity and applicability . Refine the operability of the rescue plan, practically run in the disposal measures of the relevant departments in the event of emergencies, and create a scientific and reasonable integrated underground station Policing Work point with "information and intelligence around the station as the leading, close linkage of the relevant police, integration of emergency rescue measures, sharing of equipment information resources, and high efficiency of station Policing Work". The third is the implementation of shift training. Organize the police to actively participate in the training, and at the same time, train the security personnel in the underground station of Hainan high-speed railway. In the training, the security personnel should actively cooperate with the police to enhance the tacit understanding between the two sides through continuous combat drills, so as to achieve the all-round improvement of the security force of Hainan high-speed railway underground station.

\subsection{Safety Inspection Guidance and Supervision}

Meilan station is the only underground station of Hainan Island high-speed railway, which is seamlessly connected with the airport terminal. As a preventive work, security inspection can exclude the risk factors from the station, so it is necessary to refine and improve it. The railway public security organs should strengthen the supervision and guidance of security inspection, conscientiously implement the important 
concept of "safety first", urge the railway companies to increase the investment in the construction of human and material defense technology, guide the main responsibility of security prevention of Railway internal units, strictly implement the legalization, normalization and specialization of security inspection, strictly implement the security inspection work standards, and standardize security inspection Operation process. Do a good job in the training and guidance of security service for the people, strictly implement the post approval system of security service personnel in railway companies, and achieve standardized procedures, reasonable personnel allocation, and real-time dynamic supervision. Establish the basic work mode of "every bag must be checked, every liquid must be checked, every doubt must be checked" station security inspection, as well as passenger flow guidance, risk investigation and treatment, fire safety management and other mechanisms. Through the supervision methods of "random random random inspection from time to time, adversarial secret inspection and supervision, real-time video linkage inspection", we can improve the inspection ability of safety inspection and prevent prohibited articles from entering the station and getting on the train. We should really do a good job in "people check together" and "security check in the station", and block the risk factors outside the station.

\subsection{Publicity and Education}

Doing a good job of safety education, effectively spreading legal knowledge and preaching correct safety values will help to reduce and prevent crimes. Taking the public security organs and railway enterprises as the starting point of safety education, passenger education should be strengthened by broadcasting high-speed railway safety publicity films and typical cases, and the safety awareness of passengers should be improved by means of network media or leaflets. Based on the reality and close to the front line, we should make the publicity and education work concrete and routine, and fundamentally build up the people's ideological defense line of safety.

\section{CONCLUSION}

Strengthening the security work of Meilan Airport Station and other important passenger ports is an important security guarantee for Hainan to build an international tourism island. The new era puts forward higher requirements for the Policing Work in the station area. The railway public security organs of Meilan Airport Station should base on the reality, take actual combat as the leading, promote the construction of innovative Policing Work mode, do a good job in public security prevention and control, joint service linkage, security inspection guidance supervision, anti-terrorism prevention, publicity and education, standardize the disposal of illegal acts in the station, strengthen the construction of supervision mechanism, and ensure the international security of Hainan Safe and healthy development of tourism island construction.

\section{ACKNOWLEDGEMENTS}

This paper is the phased research results of Research project of Henan Federation of Social Sciences in 2021 and Social science research project of Zhengzhou in 2021. 


\section{REFERENCES}

[1] David Canca, Alicia De-Los-Santos, Gilbert Laporte, Juan A. Mesa. Integrated Railway Rapid Transit Network Design and Line Planning problem with Maximum Profit[J]. Transportation Research Part E,2019,127.

[2] Xue Kuanli, Wang Lin, Shi Hechun.Discussion on the Mode of High-speed Railway Entering Airport[J].Civil Aviation Management,2019(02):72-77.

[3] Qiu Sanzhong. On the Standardization of Metro Police in China[D].South China University of Technology,2016.

[4] Yue Kaiming. The Research of Standardization Construction for SZX International Airport Police Work[D]. Shenzhen University,2017.

[5] William Smith. Law and (Global) Order: Towards a Theory of Cosmopolitan Policing[J]. Critical Horizons, 2016,17(1).

[6] Dai Min. Network Era of Urban Rail Transit and Construction of Active Policing Mechanism[J].Policing Studies,2009(10):16-21. 